Preprint of: Davood Rahmatabadi, Ramin Hashemi, Moslem tayyebi and Abbas Bayati. (2019). Investigation of mechanical properties, formability, and anisotropy of dual phase $\mathrm{Mg}-7 \mathrm{Li}-1 \mathrm{Zn}$. Materials Research Express. Doi: 10.1088/2053-1591/ab2de6

\title{
Investigation of mechanical properties, formability, and anisotropy of dual phase Mg-7Li-1Zn
}

\author{
D. Rahmatabadi ${ }^{1}$, R. Hashemi ${ }^{1 *}$, M. Tayyebi ${ }^{2}$, A. Bayati ${ }^{1}$ \\ ${ }^{1}$ School of Mechanical Engineering, Iran University of Science and Technology, Tehran, Iran \\ ${ }^{2}$ Department of Materials Science and Engineering, Shiraz University of Technology, Shiraz, Iran \\ *Corresponding author: \\ E-mail: rhashemi@iust.ac.ir (R. Hashemi) Tel.: +98-21-77240068, Fax: +98-21-77240540
}

\begin{abstract}
In this article, the mechanical properties, microstructure, forming limit diagram (FLD) and anisotropy of dual phase $\mathrm{Mg}-7 \mathrm{Li}-1 \mathrm{Zn}$ alloy have been evaluated by a uniaxial tensile test at three directions, scanning electron microscopy (SEM), optical microscopy (OM) and hemispherical punch test at ambient temperature. The optical microscopy images showed that the microstructure of as-cast LZ71 alloy possesses a dual phase microstructure such as $\beta$-Li matrix with bodycentered cubic $(\mathrm{BCC})$ structure and a partitioned $\alpha-\mathrm{Mg}$ phase with hexagonal closest packed $(\mathrm{HCP})$ structure in lath shape. After rolling process, the $\alpha-\mathrm{Mg}$ phase has been elongated and arranged in the rolling direction and anisotropy at different directions increased, but after full annealing, microstructure arranged more uniform and changed from elongated to the uniform structure which this is the factor that reflects the reduction of anisotropy. FLD shows the limiting surface strains that sheet metal can endure before the start of localized necking and fracture at different deformation modes in tension-tension and tension-compression loading paths. The FLD of Mg7Li-1Zn showed that this material has desirable formability due to the BCC structure with high slip system in the ambient temperature. Also, the results of the tensile test matched with the
\end{abstract}


Preprint of: Davood Rahmatabadi, Ramin Hashemi, Moslem tayyebi and Abbas Bayati. (2019). Investigation of mechanical properties, formability, and anisotropy of dual phase $\mathrm{Mg}-7 \mathrm{Li}-1 \mathrm{Zn}$. Materials Research Express. Doi: 10.1088/2053-1591/ab2de6

obtained FLD. Results of SEM revealed many dimples and some flat and cleavage planes. They showed the combination of ductile and brittle fracture, but the ductile fracture is the dominant fracture mechanisms for Mg-7Li-1Zn. In summary, in the dual phase, $\mathrm{Mg}-\mathrm{Li}$ alloys via controlling the weight percent of lithium and other alloying elements can be achieved the desired mechanical properties and used for various applications.

Keywords: Mg-7Li-1Zn alloys, Forming limit diagram, anisotropy, SEM, Microstructure, Mechanical properties.

\section{Introduction}

Magnesium alloys with a density of about $1700 \mathrm{Kg} / \mathrm{m}^{3}$ have the lowest density of applied metals. For example, magnesium density is about $20 \%, 40 \%$ and $66 \%$ of steel, titanium, and aluminum density, respectively. Also, pure magnesium is one of the most abundant metals and has favorable properties such as high durability, very high strength to weight ratio, high absorption $[1,2]$. Moreover, magnesium alloys are recyclable and light. They show desirable heat dissipation and electromagnetic shielding [1, 3-5]. Magnesium alloys are a hexagonal close-packed (HCP) structure, which leads to reduced formability in ambient temperature [3, 5-7]. Magnesium-Lithium alloy is one of the most favorable engineering metal due to its incredible properties, such as high formability and ultralow density [3, 8-10]. According to magnesium-lithium binary phase diagram, when the lithium quantity is higher than $5.7 \mathrm{wt} \%$ and lower than $11 \mathrm{wt} \%$ (between 5.7 and 11 wt. $\%)$, the microstructure is formed of the dual $\alpha-\mathrm{Mg}+\beta-\mathrm{Li}$ dual phase. The $\alpha-\mathrm{Mg}$ phase of the $\mathrm{HCP}$ structure precipitates in the matrix of the $\beta-\mathrm{Li}$, which is of a body center cubic (BCC) structure $[11,12]$. Generally, for Mg LZ dual phase alloys, $\alpha-\mathrm{Mg}$ phase with HCP structure indicates two independent slip systems and $\beta$-Li phase with BCC structure presents at least twelve 
Preprint of: Davood Rahmatabadi, Ramin Hashemi, Moslem tayyebi and Abbas Bayati. (2019). Investigation of mechanical properties, formability, and anisotropy of dual phase $\mathrm{Mg}-7 \mathrm{Li}-1 \mathrm{Zn}$. Materials Research Express. Doi: 10.1088/2053-1591/ab2de6

autonomous slip systems at room temperature [8]. Therefore, it can be concluded that more deformation at room temperature occurs in $\beta$-Li phase because $\beta$-Li phase has a higher ductility and lower strength compared to $\alpha-\mathrm{Mg}$ phase $[13,14]$. So, for $\mathrm{Mg}-\mathrm{Li}$ dual phase alloy, a high fraction of $\beta$-Li phase leads a high ductility of the alloy. This phenomenon causes the decrease of the critical shearing stress of the prismatic slip, and the slip systems are more easily activated [12]. So, $\mathrm{Mg}$-Li alloys are lighter and have higher formability than the $\mathrm{Mg}$ at room temperatures $[3,8$, 11]. These alloys show promise for the production of lightweight, portable electronic products. Furthermore, Mg-Li alloys exhibit vast application potentials in the fields of aerospace, electronics, military industry, etc. $[15,16]$. Chiu et al. investigated the effect of rolling and heat treatments of Mg LZ91 [17]. They saw that after annealing of as-rolled Mg LZ91 the $\alpha-\mathrm{Mg}$ phase with HCP structure drawn at the rolling direction and $\beta$-Li phase displayed recrystallized structure [17]. Also, the values of microhardness of both phases proportional to the cold working rate increased [17]. Most investigation on $\mathrm{Mg}-\mathrm{Li}$ alloys are about the microstructure, heat treatment and mechanical properties (similar to Chiu research) $[3,8,18]$ and the effect of adding different elements on mechanical and microstructural properties of the dual phase Mg-Li alloys [18-20], but there is no research whose primary focus is ductility and forming behavior. The ability of sheet metals to be formed into the desired shape without failure and necking is considered as sheet metal formability [21-23]. The investigation of the formability for Mg-Li alloys can be enhanced and improved the potential and practical efficacy for practical applications in industry.

The forming limit diagram (FLD) is the most popular criterion used to predict the necking initiation and the possibility of success and failure of sheet metal forming processes [24]. This plot demonstrates the combinations of major and minor surface strains that lead to fracture or necking 
Preprint of: Davood Rahmatabadi, Ramin Hashemi, Moslem tayyebi and Abbas Bayati. (2019). Investigation of mechanical properties, formability, and anisotropy of dual phase $\mathrm{Mg}-7 \mathrm{Li}-1 \mathrm{Zn}$. Materials Research Express. Doi: 10.1088/2053-1591/ab2de6

of the alloy during the forming process [25]. The FLDs could be obtained experimentally and theoretically $[26,27]$. The most well-known test to achieve FLDs empirically is an out-of-plane test (e.g., Nakazima test) in which a sheet metal specimen is fixed between circular die rings and stretched by a hemispherical punch [28, 29]. In this study, the mechanical properties, microstructure, fracture mechanism, and forming limit diagram of the as-cast $\mathrm{Mg}-\mathrm{Li}$ dual phase have been investigated at the room temperature. So, the uniaxial tensile test, scanning electron microscopy, optical microscopy, and hemispherical punch test have been used. The present work presents new results, and this paper adds them to the existing literature.

\section{Experimental procedures}

\subsection{Preparing the raw material}

The commercial pure $\mathrm{Mg}, \mathrm{Li}$, and Zinc were used to prepare $\mathrm{Mg}-7 \mathrm{Li}-1 \mathrm{Zn}$ alloy through the casting process. The flat ingots were heated to about $770^{\circ} \mathrm{C}$ in an induction furnace under an argon atmosphere, and then the melt was poured into a preheated steel mold. The chemical composition of the cast alloy was (wt $) \mathrm{Mg} 6.9 \mathrm{Li}$ and $1.1 \mathrm{Zn}$. The initial $10 \mathrm{~mm}$ thickness flat ingot was flatrolled at a rolling temperature of $250{ }^{\circ} \mathrm{C}$ to a final thickness of $2 \mathrm{~mm}$ with a total reduction of around $80 \%$ in 8 passes by $10 \%$ reduction in thickness for each rolling pass. Then, the sheet was annealed at $350{ }^{\circ} \mathrm{C}$ for 2 hours.

\subsection{Microstructure observation}

The microstructure analysis was performed using an optical and scanning electron microscope (OM and SEM). Before using optic and scanning electron microscopy, it is necessary to prepare the specimens. The samples (e.g., both the cast and as rolled $\mathrm{Mg}-7 \mathrm{Li}-1 \mathrm{Zn}$ ) were cut by wire cut 
Preprint of: Davood Rahmatabadi, Ramin Hashemi, Moslem tayyebi and Abbas Bayati. (2019). Investigation of mechanical properties, formability, and anisotropy of dual phase $\mathrm{Mg}-7 \mathrm{Li}-1 \mathrm{Zn}$. Materials Research Express. Doi: 10.1088/2053-1591/ab2de6

machining in the rolling direction. Then, they were grinding and polishing via sandpaper numbers 80 to 400 and using of a mixture of alumina powder with a particle size of $0.3 \mu \mathrm{m}$, water, and soap, respectively and finally the samples were etched. The XRD experiments were performed by an Xray diffractometer (XRD, Bruker Advance D8) using $\mathrm{Cu} k \alpha$ radiation $(\lambda=0.1542 \mathrm{~nm})$. The X-ray was operated at $40 \mathrm{kV}, 0.5$ Step Size and $40 \mathrm{~mA}$, and the data were collected at room temperature with a $2 \theta$ range between 30 and 80 . The Williamson-Hall formula and X'Pert High Score software were used to analyze the XRD data. Also, the Williamson Hall relationship (Equation 1) was used to calculate the crystallite size of processed samples after annealing and rolling. The basis of this formula is based on Full Width at Half Maximum (FWHM). In equation $1, \beta, \theta, \lambda, \varepsilon, D$ and $K$ are FWHM, diffraction angle, the wave length of X-Ray, lattice strain, crystallite size and constant about 0.9 , respectively. Sigma plot software was used to fit the peak curves and fitting the curves was done using Gaussian diagrams. An example of curve fitting by the Gaussian function are showed in Fig. 1. The first four intensity peaks were investigated to obtain $\cos \theta$ in terms of $\sin \theta$ using the Williamson Hall relationship in terms of theta. In the Fig. 2, $\cos \theta$ in terms of $\sin \theta$ were presented.

$$
\beta \cos \theta=\frac{K \lambda}{D}+4 \varepsilon \sin \theta
$$

\subsection{Mechanical characterization}

The mechanical properties of the as-cast $\mathrm{Mg}-7 \mathrm{Li}-1 \mathrm{Zn}$, after rolling process and full annealing heat treatment, were studied by uniaxial tensile tests. The uniaxial tensile test samples were prepared oriented along the rolling direction according to the ASTM E08 standard. The gauge length and width of the tensile test specimens were 10 and $4 \mathrm{~mm}$, respectively. The uniaxial tensile tests were 
Preprint of: Davood Rahmatabadi, Ramin Hashemi, Moslem tayyebi and Abbas Bayati. (2019). Investigation of mechanical properties, formability, and anisotropy of dual phase $\mathrm{Mg}-7 \mathrm{Li}-1 \mathrm{Zn}$. Materials Research Express. Doi: 10.1088/2053-1591/ab2de6

done at an initial strain rate of $0.5 \mathrm{~mm} / \mathrm{min}$ at room temperature using a SANTAM tensile testing machine. Also, to define the fracture mode for the as-cast, as-rolled, and as-annealed samples, a VEGA TESCAN SEM studied the fracture surfaces of the uniaxial tensile test samples.

\subsection{Anisotropy and Formability}

The different anisotropy parameters and coefficients for dual phase $\mathrm{Mg}$-7Li-1Zn alloy after rolling and thermal treatment were determined experimentally. For this purpose, the uniaxial tensile test was performed in all three directions ( $\mathrm{RD}, 45^{\circ}$ and $\left.\mathrm{TD}\right)$ and the longitudinal and transverse strain, were measured after $15 \%$ elongation. According to Equation (2), R-value was calculated as the thickness strain to transverse ratio. A thickness strain was obtained using constant volume law in plastic deformation. By calculating the anisotropy coefficients in three directions, according to Equation (3) and (4), two other parameters such as average plastic strain and planer anisotropy, could be calculated.

$$
\begin{aligned}
& \text { Rvalue }=\frac{\varepsilon_{w}}{\varepsilon_{t}}=\frac{\varepsilon_{w}}{-\varepsilon_{l}-\varepsilon_{w}} \\
& r_{m}=\left|\frac{r_{R D}+r_{T D}+2 r_{45}}{4}\right| \\
& \Delta \mathrm{r}=\left|\frac{r_{R D}+r_{T D}-2 r_{45}}{2}\right|
\end{aligned}
$$

The Nakazima test was utilized to draw the FLD. The stages of determining the FLD included preparing samples, marking the samples, doing the biaxial stretch-forming tests, reading strains, and finally drawing the corresponding FLD [24, 30]. According to Fig. 3 samples with different geometries (include rectangular samples with different widths) were used to obtain the FLD. The 
Preprint of: Davood Rahmatabadi, Ramin Hashemi, Moslem tayyebi and Abbas Bayati. (2019). Investigation of mechanical properties, formability, and anisotropy of dual phase $\mathrm{Mg}-7 \mathrm{Li}-1 \mathrm{Zn}$. Materials Research Express. Doi: 10.1088/2053-1591/ab2de6

specimens were cut by wire cut machine from the sheet metals $50 \mathrm{~mm}$ in length, corresponding to one-fourth of ISO 12004 standard dimensions [21, 24]. Also, as shown in Fig.3, to mark the circular grid with one inch $(2.5 \mathrm{~mm})$ diameter and a depth of 1 micrometer over the surface of fully annealed Mg LZ 71, the electrochemical procedure was used. For stretching sheet samples, a SANTAM S20 50_ton constant speed hydraulic press machine equipped with a displacement-force curve and two mm/min speed was employed. As shown in Fig. 4, an abrupt change in the loaddisplacement diagram was utilized as the stopping criterion in the test. Typical deformed samples after Nakazima test are shown in Fig. 5. The circular grids were deformed to elliptic shapes. According to Fig. 6 after conducting the out-of-plane stretching analysis for each sample, the limited strains were determined from the major and minor axes of the ellipse, located nearest to the localized necking region, using a traveling microscope with an accuracy of $1 \mu \mathrm{m}$. The major and minor true strains were calculated via Eqs. (5-8):

$$
\begin{gathered}
e_{\text {Major }}=\frac{a-d}{d} \times 100 \\
e_{\text {Minor }}=\frac{b-d}{d} \times 100 \\
\varepsilon_{\text {Major }}=\ln \left(1+e_{\text {Major }}\right) \\
\varepsilon_{\text {Minor }}=\ln \left(1+e_{\text {Minor }}\right)
\end{gathered}
$$

" $a, "$ " $b$," and " $d$ " introduce the ellipse's major and minor diameters and the initial circle diameter, respectively.

\section{Results and discussion}


Preprint of: Davood Rahmatabadi, Ramin Hashemi, Moslem tayyebi and Abbas Bayati. (2019). Investigation of mechanical properties, formability, and anisotropy of dual phase $\mathrm{Mg}-7 \mathrm{Li}-1 \mathrm{Zn}$. Materials Research Express. Doi: 10.1088/2053-1591/ab2de6

\subsection{Microstructure and mechanical properties}

Fig. 7 demonstrated the optical microstructure of the as-cast dual phase $\mathrm{Mg}$-7Li-1Zn sample. The microstructure of the as-cast $\mathrm{Mg}-7 \mathrm{Li}-1 \mathrm{Zn}$ alloy showed a dual phase microstructure such as $\alpha-\mathrm{Mg}$ (Mg solid solution) with HCP structure and $\beta$-Li (Li solid solution) phase with BCC structure. The bright and dark phase of the microstructure specified $\alpha-\mathrm{Mg}$ and $\beta-\mathrm{Li}$, respectively. According to Fig. 7 the microstructures of the as-cast $\mathrm{Mg}$-7Li-1Zn have included a $\beta$-Li matrix phase and a partitioned $\alpha-\mathrm{Mg}$ phase in lath shape. Fig 8 demonstrated the microstructure of the as-rolled sample (e.g., Fig. (a) and (b)), and as-annealed samples (e.g., Fig. (c) and (d)). Fig. 8(a) and (b) showed that after rolling $\alpha-\mathrm{Mg}$ phase was elongated and arranged in the rolling direction (RD) and the lath form was removed. After annealing the recrystallization occurred in the $\beta$-Li matrix phase, and also $\alpha$-Mg phase arranged more uniform and changed from elongated to uniform structure [17]. Fig. 9, showed the X-Ray diffraction of as annealed dual phase Mg-7Li-1Zn sample. This image also shows two main phases $\alpha-\mathrm{Mg}$ and $\beta$ - $\mathrm{Li}$ and $\mathrm{MgLi}_{2} \mathrm{Zn}$ phase. The most intense $\mathrm{BCC}-\mathrm{Mg}$ and weak Magnesium oxide diffraction peaks were identified. Also, the presence of the $\mathrm{MgLi}_{2} \mathrm{Zn}$ phase increased the strength and hardness which would refer to the impact of this phase on mechanical properties, although its amount was very small and not visible on optical microscope images [16, $31]$.

The engineering stress-strain curves for the as-cast $\mathrm{Mg}-7 \mathrm{Li}-1 \mathrm{Zn}$, the as-rolled, and the fully annealed material are demonstrated in Fig. 10. According to Fig. 10, the elongation and ultimate tensile strength (UTS) were determined. The elongation of the as-cast $\mathrm{Mg}-7 \mathrm{Li}-1 \mathrm{Zn}$ sample was very high compared to other $\mathrm{Mg}$ alloys, although the as-cast samples have a defect such as porosity, non-uniform structure, etc. For Mg-7Li-1Zn dual phase alloys, $\alpha$-Mg phase with HCP structure 
Preprint of: Davood Rahmatabadi, Ramin Hashemi, Moslem tayyebi and Abbas Bayati. (2019). Investigation of mechanical properties, formability, and anisotropy of dual phase $\mathrm{Mg}-7 \mathrm{Li}-1 \mathrm{Zn}$. Materials Research Express. Doi: 10.1088/2053-1591/ab2de6

indicated two independent slip systems and $\beta$-Li phase with BCC structure presents at least twelve autonomous slip systems at room temperature, so $\mathrm{Mg}$ alloys containing the $\mathrm{BCC}$ structure such as Mg-Li could have more ductility [8]. Also, it could be concluded that more elongation at room temperature that was occurred due to $\beta$ - $\mathrm{Li}$ phase. To decrease the porosity, as-cast $\mathrm{Mg}-7 \mathrm{Li}-1 \mathrm{Zn}$ were hot rolled in $250^{\circ} \mathrm{C}$ for eight passes that the reduced thickness is about $10 \%$ in each pass (i.e., $80 \%$ total reduction). As anticipated, the strength and elongation of $\mathrm{Mg}-7 \mathrm{Li}-1 \mathrm{Zn}$ after rolling increased and decreased, respectively, due to work hardening [32-37]. The strength after rolling reached to $180 \mathrm{MPa}$ that was two times higher than the as-cast material. Also, the elongation decreased from $25 \%$ to $20 \%$. After rolling due to reach the more homogeneity of microstructure, the sample was fully being annealed. The crystallite size obtained by the Williamson Hall relationship for the alpha phase in annealing and after rolling is 86 and $65 \mathrm{~nm}$, respectively, which shows the effect of the rolling process on microstructure developments. Plastic deformation processes such as rolling could degrade the alpha phase grains, as well as increase the dislocation density of the beta phase, and ultimately cause the dual phase $\mathrm{Mg}-7 \mathrm{Li}-1 \mathrm{Zn}$ would be strengthening $[1,38]$. After annealing due to deleting the effect of work hardening, strength decreased, and elongation increased. Finally, the strength and elongation reached to $150 \mathrm{MPa}$ and $30 \%$ after full annealing.

Another strengthening mechanism was the solid solution and intermetallic layers. In the Mg-7Li$1 \mathrm{Zn}$, the presence of the $\mathrm{MgLi}_{2} \mathrm{Zn}$ phase increased the strength and hardness. $\mathrm{Zn}$ has a better strengthening effect than other elements used in two-phase $\mathrm{Mg}$-Li alloys and can achieve a combination of good strength and ductility. In Table 1, the mechanical properties (strength and 
Preprint of: Davood Rahmatabadi, Ramin Hashemi, Moslem tayyebi and Abbas Bayati. (2019). Investigation of mechanical properties, formability, and anisotropy of dual phase $\mathrm{Mg}-7 \mathrm{Li}-1 \mathrm{Zn}$. Materials Research Express. Doi: 10.1088/2053-1591/ab2de6

elongation) of different two-phase magnesium-lithium alloys were compared under various deformation operations, such as rolling and extrusion. As can be seen, by increasing the percentage of Li the strength of $\mathrm{Mg}$ - $\mathrm{Li}$ alloys decreased and elongation increased as the volume of the beta phase was higher than the alpha, and the beta phase was weaker. Also, mechanical work and plastic deformation could cause the grain refinement and increased density dislocation in the alpha and the beta phase. In short, the alpha phase had good strength, and the beta phase had excellent ductility, and different $\mathrm{Mg}$-Li alloys could be used to the various application via required strength and ductility.

\subsection{Fractography}

The SEM image of tensile fracture surfaces of $\mathrm{Mg}-7 \mathrm{Li}-1 \mathrm{Zn}$ in three different situations (as-cast, as-rolled, and as-annealed) are presented in Fig. 11. For the dual phase alloys, ductility and formability have affected both phases, in particular, the phase of high formability. The fracture mechanism of magnesium alloys is always in the brittle mode showing the patterns of cleavage and quasi-cleavage [8]. Generally, for Mg LZ dual phase alloys, $\alpha-\mathrm{Mg}$ phase with HCP (hexagonal close-packed) structure indicates two independent slip systems and $\beta$-Li phase with BCC (body center cubic) structure presents at least twelve independent slip systems at room temperature [8]. Therefore, it can be concluded that more deformation at room temperature occurs in $\beta$-Li phase because $\beta$-Li phase has a higher ductility and lower strength compared to $\alpha$-Mg phase. So, for $\mathrm{Mg}$ 7Li-1Zn dual phase, a high fraction of $\beta$-Li phase leads a high ductility of the alloy. According to Fig. 9 (a-c), the very dimples and some flat and cleavage planes were observed that it shows the combination of ductile and brittle fracture, but the ductile fracture is the dominant fracture mechanisms for Mg-7Li-1Zn. Also, the failure mechanism was the same and was a brittle mode in 
Preprint of: Davood Rahmatabadi, Ramin Hashemi, Moslem tayyebi and Abbas Bayati. (2019). Investigation of mechanical properties, formability, and anisotropy of dual phase $\mathrm{Mg}-7 \mathrm{Li}-1 \mathrm{Zn}$. Materials Research Express. Doi: 10.1088/2053-1591/ab2de6

all three images (Fig. 11(a-c)). However, the size, depth, and several cavities and dimples were different. For the as-annealed samples, the depth and number of dimples were much more than the as rolled and the as-cast samples which indicated the better ductility for annealed Mg-7Li-1Zn.

\subsection{Anisotropy and Formability}

The different anisotropy coefficients such as $\mathrm{R}$-value, $\mathrm{R}_{\mathrm{m}}$ (normal), and $\Delta \mathrm{R}$ of the dual phase $\mathrm{Mg}$ Li alloys are shown in Table 2 . They were determined experimentally after rolling and annealing. According to Table 2, different anisotropy coefficients after rolling are far higher than after annealing. In other words, performing heat treatment reduces anisotropy in all directions. By annealing, the more uniform structures of alpha and beta phase are formed, and anisotropy decreased sharply. Also, the HCP structure of the alpha phase creates high anisotropy during the rolling process. According to Table 2, after rolling high anisotropy was formed, which was respectively the highest at 45 degrees, rolling direction, and transverse direction. By annealing, $\mathrm{R}$ value decreased at all three directions, and the R-values were very close.

Forming limit diagram shows the limiting surface strains that sheet metal can endure before the start of localized necking and fracture at different deformation modes in tension-tension and tension-compression loading paths $[46,47]$. The forming limit diagram of the full annealed $\mathrm{Mg}$ 7Li-1Zn alloy at room temperature from the experimental Nakazima test results is shown in Fig. 12. The FLD demonstrates the combinations of major and minor surface strains that lead to fracture of the Mg-7Li-1Zn. The right and left side of this diagram are determined by the positive and negative minor strains, respectively. Also, there are many strain paths to biaxial and uniaxial tension from the plane strain. In the biaxial tensile region (tension-tension), the maximum surface 
Preprint of: Davood Rahmatabadi, Ramin Hashemi, Moslem tayyebi and Abbas Bayati. (2019). Investigation of mechanical properties, formability, and anisotropy of dual phase $\mathrm{Mg}-7 \mathrm{Li}-1 \mathrm{Zn}$. Materials Research Express. Doi: 10.1088/2053-1591/ab2de6

major and minor strains are about $14.49 \%$ and $23.98 \%$, respectively. In the uniaxial tensile region (tension-compression), the maximum major and minor strains are about $26.18 \%$ and $21.91 \%$, respectively. Also, for the near plane strain region (minor strain is about zero), the minimum minor strain is about $11.09 \%$. For the dual phase alloys, ductility and formability are affected both phases, in particular, the phase of high formability. Therefore, more formability of $\mathrm{Mg}-7 \mathrm{Li}-1 \mathrm{Zn}$ could be related to dual phases, especially $\beta$-Li phase with BCC structure.

\section{Conclusion}

In the present study, the mechanical properties, microstructure anisotropy, and formability of the as-cast dual phase $\mathrm{Mg}-7 \mathrm{Li}-1 \mathrm{Zn}$ alloy were studied. The primary goal of this study was to examine the formability of dual phase $\mathrm{Mg} \mathrm{LZ}$ alloy by forming limit diagram. The OM images demonstrated that microstructure of the as-cast LZ71 alloy possesses a dual phase such as $\beta$-Li matrix with BCC structure and a partitioned $\alpha-\mathrm{Mg}$ phase with HCP structure in lath shape. After annealing the more uniform structure of the alpha and beta phase is formed, and the created anisotropy during rolling also drastically decreases. Results of FLD showed that Mg-7Li-1Zn has desirable formability due to the $\mathrm{BCC}$ structure of $\beta$-Li matrix with high slip system in the ambient temperature. Also, the results of the tensile test matched with FLD. As anticipated, the strength and elongation of the ascast $\mathrm{Mg}-7 \mathrm{Li}-1 \mathrm{Zn}$ after rolling increased and decreased, respectively, due to work hardening. The strength after rolling would reach to $180 \mathrm{MPa}$ that is two times higher than the as-cast material. Finally, the strength and elongation reached to $150 \mathrm{MPa}$ and $30 \%$ after full annealing. The $\beta$-Li and $\alpha-\mathrm{Mg}$ phase played a role in the improvement of ductility and strength, respectively. Because the $\beta$-Li phase has a higher ductility and lower strength compared to the $\alpha$-Mg phase. The SEM 
Preprint of: Davood Rahmatabadi, Ramin Hashemi, Moslem tayyebi and Abbas Bayati. (2019). Investigation of mechanical properties, formability, and anisotropy of dual phase $\mathrm{Mg}-7 \mathrm{Li}-1 \mathrm{Zn}$. Materials Research Express. Doi: 10.1088/2053-1591/ab2de6

images showed very dimples. So, the ductile fracture is the dominant fracture mode for $\mathrm{Mg}-7 \mathrm{Li}$ $1 \mathrm{Zn}$.

\section{Reference}

[1] Rahmatabadi, D., Tayyebi, M., Hashemi, R. and Faraji, G., "Microstructure and Mechanical Properties of $\mathrm{Al} / \mathrm{Cu} / \mathrm{Mg}$ Laminated Composite Sheets Produced by the Arb Proces“ International Journal of Minerals, Metallurgy, and Materials, Vol. 25, No. 5, pp. 564-572, 2018.

[2] Abedi, H. R., Zarei-Hanzaki, A. and Khoddam, S., "Effect of $\Gamma$ Precipitates on the Cavitation Behavior of Wrought Az31 Magnesium Alloy“ Materials and Design, Vol. 32, No. 4, pp. 2181-2190, 2011.

[3] Lin, M.-C., Lin, S.-Q. and Uan, J.-Y., "Effect of Annealing Temperature on the Microstructure and Mechanical Properties of an as-Rolled Mg-9wt.\% Li-3wt.\% Al-1wt.\% Zn Alloy Sheet“" Frontiers of Materials Science, Vol. 8, No. 3, pp. 271-280, 2014.

[4] Kojima, Y., "Platform Science and Technology for Advanced Magnesium Alloys" in Proceeding of Trans Tech Publ, pp. 3-18.

[5] Mordike, B. and Ebert, T., "Magnesium: Properties-Applications-Potential" Materials Science and Engineering: A, Vol. 302, No. 1, pp. 37-45, 2001.

[6] Rahmatabadi, D., Tayyebi, M., Sheikhi, A. and Hashemi, R., "Fracture Toughness Investigation of Al1050/Cu/Mgaz31zb Multi-Layered Composite Produced by Accumulative Roll Bonding Process“" Materials Science and Engineering: A, Vol. 734, pp. 427-436, 2018/09/12/, 2018.

[7] Khoshzaban Khosroshahi, H., Fereshteh Saniee, F. and Abedi, H. R., "Mechanical Properties Improvement of Cast Az80 Mg Alloy/Nano-Particles Composite Via Thermomechanical Processing" Materials Science and Engineering A, Vol. 595, pp. 284290, 2014. 
Preprint of: Davood Rahmatabadi, Ramin Hashemi, Moslem tayyebi and Abbas Bayati. (2019). Investigation of mechanical properties, formability, and anisotropy of dual phase $\mathrm{Mg}-7 \mathrm{Li}-1 \mathrm{Zn}$. Materials Research Express. Doi: 10.1088/2053-1591/ab2de6

[8] Wang, T., Zhu, T., Wu, R., Miao, W., Zhang, J. and Zhang, M., "Microstructure and Mechanical Properties of La51 and La51-0.5 Y Alloys with Different Accumulated Strains and Rolling Temperatures“، Materials \& Design, Vol. 85, pp. 190-196, 2015.

[9] Wu, R.-Z., Yan, Y.-d., Wang, G.-X., Murr, L. E., Han, W., Zhang, Z.-w. and Zhang, M.-1., "Recent Progress in Magnesium-Lithium Alloys“ International Materials Reviews, Vol. 60, No. 2, pp. 65-100, 2015.

[10] Nene, S., Kashyap, B., Prabhu, N., Estrin, Y. and Al-Samman, T., "Microstructure Refinement and Its Effect on Specific Strength and Bio-Corrosion Resistance in Ultralight Mg-4li-1ca (Lc41) Alloy by Hot Rolling“ Journal of Alloys and Compounds, Vol. 615, pp. 501-506, 2014.

[11] Massalski, T., "Binary Alloy Phase Diagrams Vol 3 (Ohio: Asm International, Materials Park)“, 1990.

[12] Yang, Z., Li, J., Zhang, J., Lorimer, G. and Robson, J., "Review on Research and Development of Magnesium Alloys“ Acta Metallurgica Sinica (English Letters), Vol. 21, No. 5, pp. 313-328, 2008.

[13] Pahlavani, M., Marzbanrad, J., Rahmatabadi, D., Hashemi, R. and Bayati, A., “A Comprehensive Study on the Effect of Heat Treatment on the Fracture Behaviors and Structural Properties of Mg-Li Alloys Using Rsm“"Materials Research Express, Vol. 6, No. 7, 2019.

[14] Rahmatabadi, D., Pahlavani, M., Bayati, A., Hashemi, R. and Marzbanrad, J., "Evaluation of Fracture Toughness and Rupture Energy Absorption Capacity of as-Rolled Lz71 and Lz91 Mg Alloy Sheet“" Materials Research Express, Vol. 6, No. 3, 2019.

[15] $\mathrm{Xu}, \mathrm{D}$. and Han, E., "Effect of Quasicrystalline Phase on Improving the Corrosion Resistance of a Duplex Structured Mg-Li Alloy“ Scripta Materialia, Vol. 71, pp. 21-24, 2014.

[16] Takuda, H., Matsusaka, H., Kikuchi, S. and Kubota, K., "Tensile Properties of a Few MgLi-Zn Alloy Thin Sheets“ Journal of materials science, Vol. 37, No. 1, pp. 51-57, 2002. 
Preprint of: Davood Rahmatabadi, Ramin Hashemi, Moslem tayyebi and Abbas Bayati. (2019). Investigation of mechanical properties, formability, and anisotropy of dual phase $\mathrm{Mg}-7 \mathrm{Li}-1 \mathrm{Zn}$. Materials Research Express. Doi: 10.1088/2053-1591/ab2de6

[17] Chiu, C.-H., Wu, H.-Y., Wang, J.-Y. and Lee, S., "Microstructure and Mechanical Behavior of Lz91 Mg Alloy Processed by Rolling and Heat Treatments“ Journal of Alloys and Compounds, Vol. 460, No. 1-2, pp. 246-252, 2008.

[18] Chang, T.-C., Wang, J.-Y., Chu, C.-L. and Lee, S., "Mechanical Properties and Microstructures of Various Mg-Li Alloys“" Materials Letters, Vol. 60, No. 27, pp. 32723276, 2006.

[19] Zhao, Z., Sun, Z., Liang, W., Wang, Y. and Bian, L., "Influence of Al and Si Additions on the Microstructure and Mechanical Properties of Mg-4li Alloys“ Materials Science and Engineering: A, Vol. 702, pp. 206-217, 2017.

[20] Charles, M., Hao, G., Yun, Z., Songsong, X. and ZHANG, Z., "Effects of Holmium and Hot-Rolling on Microstructure and Mechanical Properties of Mg-Li Based Alloys“ Journal of Rare Earths, Vol. 34, No. 12, pp. 1269-1276, 2016.

[21] Rahimi, H., Sedighi, M. and Hashemi, R., "Forming Limit Diagrams of Fine-Grained Al 5083 Produced by Equal Channel Angular Rolling Process“ Proceedings of the Institution of Mechanical Engineers, Part L: Journal of Materials Design and Applications, pp. 1464420716655560, 2016.

[22] Karajibani, E., Hashemi, R. and Sedighi, M., "Forming Limit Diagram of AluminumCopper Two-Layer Sheets: Numerical Simulations and Experimental Verifications“ The International Journal of Advanced Manufacturing Technology, Vol. 90, No. 9-12, pp. 2713-2722, 2017.

[23] Afshar, A., Hashemi, R., Madoliat, R., Rahmatabadi, D. and Hadiyan, B., "Numerical and Experimental Study of Bursting Prediction in Tube Hydroforming of Al 7020-T6“ Mechanics \& Industry, Vol. 18, No. 4, pp. 411, 2017.

[24] Rahmatabadi, D. and Hashemi, R., "Experimental Evaluation of Forming Limit Diagram and Mechanical Properties of Nano/Ultra-Fine Grained Aluminum Strips Fabricated by Accumulative Roll Bonding“ International Journal of Materials Research, Vol. 108, No. 12, pp. 1036-1044, 2017.

[25] Keeler, S. P., "Determination of Forming Limits in Automotive Stampings“ 0148-7191, SAE Technical Paper, pp. 1965. 
Preprint of: Davood Rahmatabadi, Ramin Hashemi, Moslem tayyebi and Abbas Bayati. (2019). Investigation of mechanical properties, formability, and anisotropy of dual phase $\mathrm{Mg}-7 \mathrm{Li}-1 \mathrm{Zn}$. Materials Research Express. Doi: 10.1088/2053-1591/ab2de6

[26] Hashemi, R., Mamusi, H. and Masoumi, A., "A Simulation-Based Approach to the Determination of Forming Limit Diagrams“ Proceedings of the Institution of Mechanical Engineers, Part B: Journal of Engineering Manufacture, pp. 0954405414522448, 2014.

[27] Habibi, M., Hashemi, R., Ghazanfari, A., Naghdabadi, R. and Assempour, A., "Forming Limit Diagrams by Including the M-K Model in Finite Element Simulation Considering the Effect of Bending" Proceedings of the Institution of Mechanical Engineers, Part L: Journal of Materials: Design and Applications, Vol. 232, No. 8, pp. 625-636, 2018.

[28] Zhang, C., Leotoing, L., Guines, D. and Ragneau, E., "Theoretical and Numerical Study of Strain Rate Influence on Aa5083 Formability“ Journal of materials processing technology, Vol. 209, No. 8, pp. 3849-3858, 2009.

[29] Hashemi, R., Ghazanfari, A., Abrinia, K. and Assempour, A., "Forming Limit Diagrams of Ground St14 Steel Sheets with Different Thicknesses" SAE International Journal of Materials and Manufacturing, Vol. 5, No. 1, pp. 60-64, 2012.

[30] Hashemi, R., Faraji, G., Abrinia, K. and Dizaji, A. F., "Application of the Hydroforming Strain-and Stress-Limit Diagrams to Predict Necking in Metal Bellows Forming Process“ The International Journal of Advanced Manufacturing Technology, Vol. 46, No. 5-8, pp. 551-561, 2010.

[31] Kúdela Jr, S., Švec, P., Bajana, O., Orovčík, L., Ranachowski, P. and Ranachowski, Z., "Strengthening in Dual-Phase Structured Mg-Li-Zn Alloys" Kovove Mater, Vol. 54, pp. 483-489, 2016.

[32] Rahmatabadi, D., Tayyebi, M., Hashemi, R. and Faraji, G., "Evaluation of Microstructure and Mechanical Properties of Multilayer A15052-Cu Composite Produced by Accmulative Roll Bonding“" Powder Metallurgy and Metal Ceramics, Vol. 57, No. 3-4, pp. 144-153, 2018.

[33] Rahmatabadi, D., Hashemi, R., Mohammadi, B. and Shojaee, T., "Experimental Evaluation of the Plane Stress Fracture Toughness for Ultra-Fine Grained Aluminum Specimens Prepared by Accumulative Roll Bonding Process“" Materials Science and Engineering: A, Vol. 708, pp. 301-310, 2017. 
Preprint of: Davood Rahmatabadi, Ramin Hashemi, Moslem tayyebi and Abbas Bayati. (2019). Investigation of mechanical properties, formability, and anisotropy of dual phase $\mathrm{Mg}-7 \mathrm{Li}-1 \mathrm{Zn}$. Materials Research Express. Doi: 10.1088/2053-1591/ab2de6

[34] Rahmatabadi, D., Mohammadi, B., Hashemi, R. and Shojaee, T., "An Experimental Study of Fracture Toughness for Nano/Ultrafine Grained A15052/Cu Multilayered Composite Processed by Accumulative Roll Bonding“ Journal of Manufacturing Science and Engineering, Vol. 140, No. 10, pp. 101001-101001-11, 2018.

[35] Su, Q., Xu, J., Li, Y., Yoon, J. I., Shan, D., Guo, B. and Kim, H. S., "Microstructural Evolution and Mechanical Properties in Superlight Mg-Li Alloy Processed by HighPressure Torsion“"Materials, Vol. 11, No. 4, pp. 598, 2018.

[36] Rahmatabadi, D., Shahmirzaloo, A., Farahani, M., Tayyebi, M. and Hashemi, R., "Characterizing the Elastic and Plastic Properties of the Multilayered Al/Brass Composite Produced by Arb Using Dic“" Materials Science and Engineering A, Vol. 753, pp. 70-78, 2019.

[37] Rahmatabadi, D., Shahmirzaloo, A., Hashemi, R. and Farahani, M., "Using Digital Image Correlation for Characterizing the Elastic and Plastic Parameters of Ultrafine-Grained Al 1050 Strips Fabricated Via Accumulative Roll Bonding Process“ Materials Research Express, Vol. 6, No. 8, pp. 086542, 2019/05/08, 2019.

[38] Farshidi, M. H., Kazeminezhad, M. and Miyamoto, H., "Severe Plastic Deformation of 6061 Aluminum Alloy Tube with Pre and Post Heat Treatments" Materials Science and Engineering: A, Vol. 563, pp. 60-67, 2013.

[39] Dong, H., Pan, F., Jiang, B. and Zeng, Y., "Evolution of Microstructure and Mechanical Properties of a Duplex Mg-Li Alloy under Extrusion with an Increasing Ratio“ Materials \& Design, Vol. 57, pp. 121-127, 2014.

[40] Takuda, H., Kikuchi, S., Tsukada, T., Kubota, K. and Hatta, N., "Effect of Strain Rate on Deformation Behaviour of a Mg-8.5 Li-1zn Alloy Sheet at Room Temperature" Materials Science and Engineering: A, Vol. 271, No. 1-2, pp. 251-256, 1999.

[41] Liu, Y., Wu, Y., Bian, D., Gao, S., Leeflang, S., Guo, H., Zheng, Y. and Zhou, J., "Study on the Mg-Li-Zn Ternary Alloy System with Improved Mechanical Properties, Good Degradation Performance and Different Responses to Cells“ Acta biomaterialia, Vol. 62, pp. 418-433, 2017. 
Preprint of: Davood Rahmatabadi, Ramin Hashemi, Moslem tayyebi and Abbas Bayati. (2019). Investigation of mechanical properties, formability, and anisotropy of dual phase $\mathrm{Mg}-7 \mathrm{Li}-1 \mathrm{Zn}$. Materials Research Express. Doi: 10.1088/2053-1591/ab2de6

[42] Takuda, H., Enami, T., Kubota, K. and Hatta, N., "The Formability of a Thin Sheet of Mg-8.5 Li-1zn Alloy“ Journal of Materials Processing Technology, Vol. 101, No. 1-3, pp. 281-286, 2000.

[43] Kubota, K., Mabuchi, M. and Higashi, K., "Review Processing and Mechanical Properties of Fine-Grained Magnesium Alloys“ Journal of Materials Science, Vol. 34, No. 10, pp. 2255-2262, 1999.

[44] Wu, R., Qu, Z. and Zhang, M., "Effects of the Addition of Y in Mg-8li-(1, 3) Al Alloy" Materials Science and Engineering: A, Vol. 516, No. 1-2, pp. 96-99, 2009.

[45] Zhang, M., Wu, R. and Wang, T., "Microstructure and Mechanical Properties of Mg-8li(0-3) Ce Alloys“" Journal of materials science, Vol. 44, No. 5, pp. 1237-1240, 2009.

[46] Zhalehfar, F., Hashemi, R. and Hosseinipour, S. J., "Experimental and Theoretical Investigation of Strain Path Change Effect on Forming Limit Diagram of Aa5083، International Journal of Advanced Manufacturing Technology, Vol. 76, No. 5-8, pp. 1343$1352,2014$.

[47] Habibi, M., Hashemi, R., Fallah Tafti, M. and Assempour, A., "Experimental Investigation of Mechanical Properties, Formability and Forming Limit Diagrams for Tailor-Welded Blanks Produced by Friction Stir Welding“ Journal of Manufacturing Processes, Vol. 31, pp. 310-323, 2018. 
Preprint of: Davood Rahmatabadi, Ramin Hashemi, Moslem tayyebi and Abbas Bayati. (2019). Investigation of mechanical properties, formability, and anisotropy of dual phase Mg-7Li-1Zn. Materials Research Express. Doi: 10.1088/2053-1591/ab2de6

\section{List of figures}

Fig.1 An example of curve fitting by the Gaussian function (the red and black curves are after and before fitting)

Fig.2 The $\cos \theta$ in terms of $\sin \theta$ by the linear trend line of Williamson Hall relationship

Fig.3 Typical prepared specimens for the Nakazima test

Fig.4 The force-displacement during the Nakazima test for different samples

Fig.5 Typical processed specimens by the Nakazima test

Fig.6 The necking and fracture points after the Nakazima test

Fig.7 The microstructure of the as-cast $\mathrm{Mg}-7 \mathrm{Li}-1 \mathrm{Zn}$

Fig.8 The microstructure of Mg-7Li-1Zn: (a) and (b) as rolled samples; (c) and (d) full annealed samples

Fig.9 The X-ray-diffraction of the full annealed $\mathrm{Mg}-7 \mathrm{Li}-1 \mathrm{Zn}$ sample

Fig.10 The engineering stress-strain curves of Mg-7Li-1Zn for three different situations (as-cast, as rolled and full annealed sample)

Fig.11 The tensile fracture surfaces of $\mathrm{Mg}-7 \mathrm{Li}-1 \mathrm{Zn}$ for three different cases: (a) as-cast, (b) as rolled and (c) full annealed sample

Fig.12 The forming limit diagram of full annealed Mg-7Li-1Zn 
Preprint of: Davood Rahmatabadi, Ramin Hashemi, Moslem tayyebi and Abbas Bayati. (2019). Investigation of mechanical properties, formability, and anisotropy of dual phase $\mathrm{Mg}-7 \mathrm{Li}-1 \mathrm{Zn}$. Materials Research Express. Doi: 10.1088/2053-1591/ab2de6

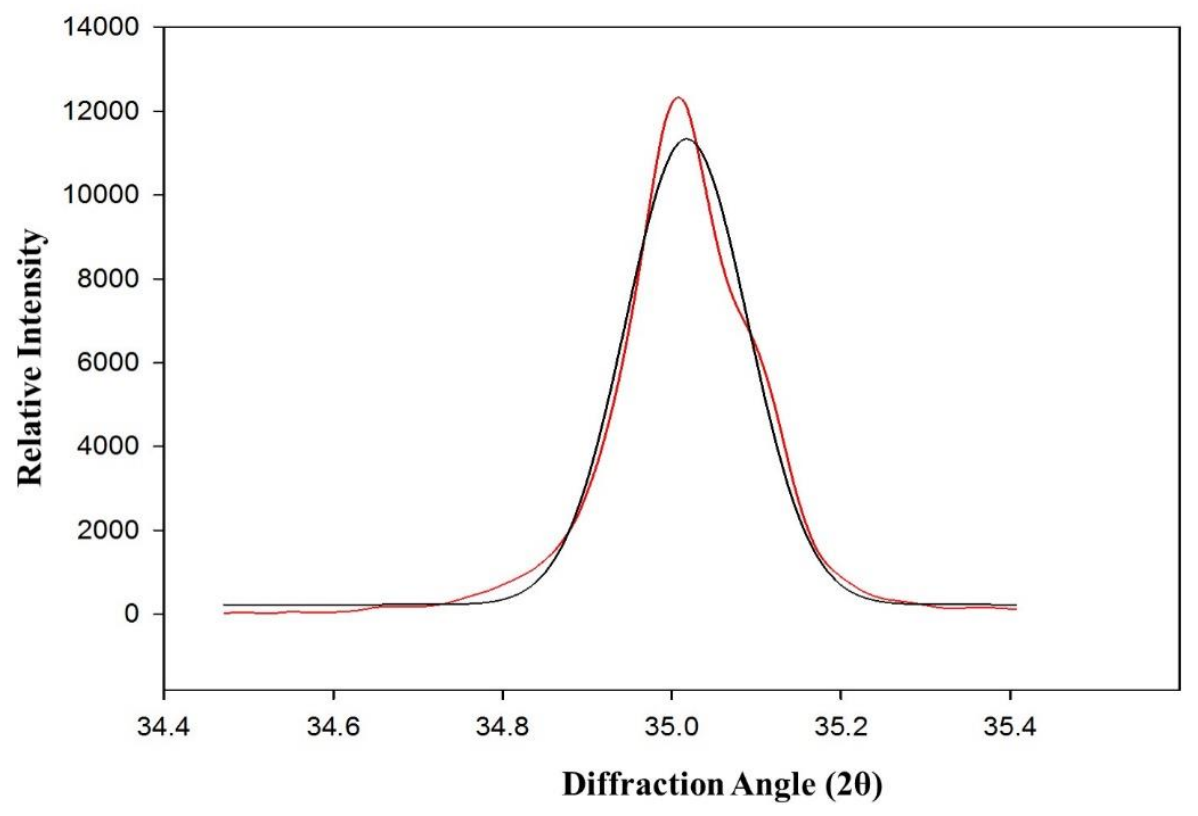

Fig.1 An example of curve fitting by the Gaussian function (the red and black curves are after and before fitting) 
Preprint of: Davood Rahmatabadi, Ramin Hashemi, Moslem tayyebi and Abbas Bayati. (2019). Investigation of mechanical properties, formability, and anisotropy of dual phase $\mathrm{Mg}-7 \mathrm{Li}-1 \mathrm{Zn}$. Materials Research Express. Doi: 10.1088/2053-1591/ab2de6

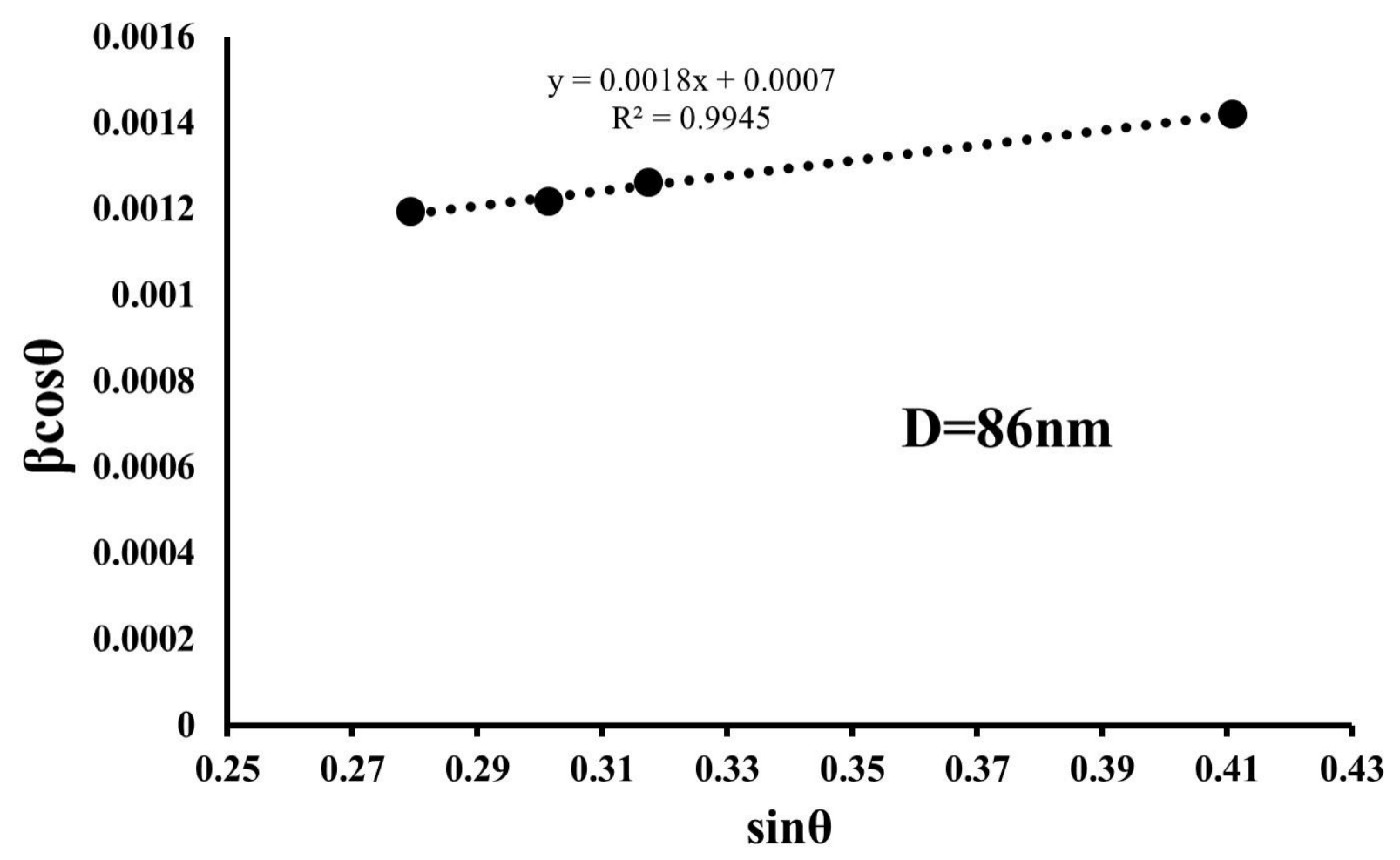

Fig.2 The $\cos \theta$ in terms of $\sin \theta$ by the linear trend line of Williamson Hall relationship 
Preprint of: Davood Rahmatabadi, Ramin Hashemi, Moslem tayyebi and Abbas Bayati. (2019). Investigation of mechanical properties, formability, and anisotropy of dual phase $\mathrm{Mg}-7 \mathrm{Li}-1 \mathrm{Zn}$. Materials Research Express. Doi: 10.1088/2053-1591/ab2de6

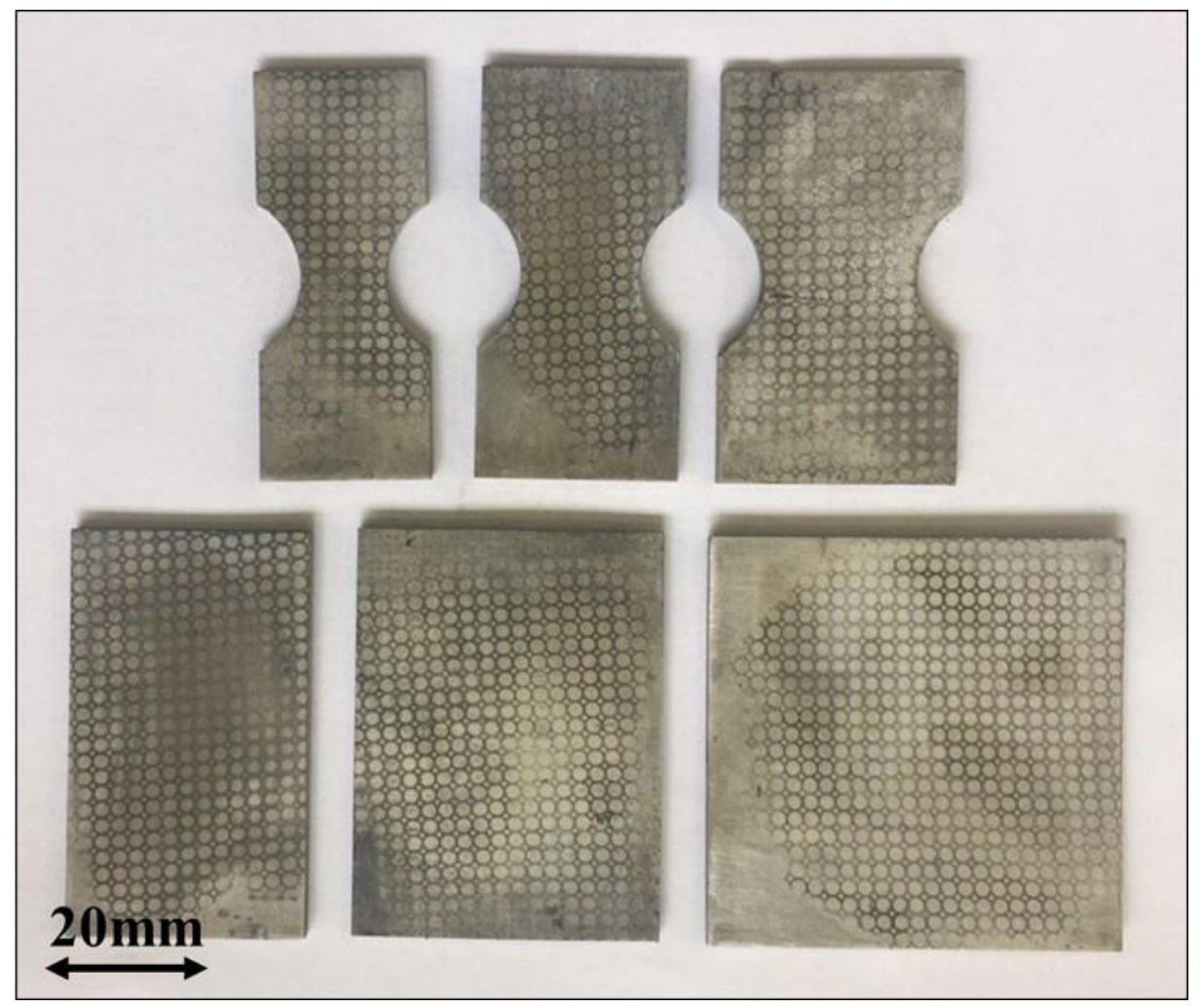

Fig.3 Typical prepared specimens for the Nakazima test 
Preprint of: Davood Rahmatabadi, Ramin Hashemi, Moslem tayyebi and Abbas Bayati. (2019). Investigation of mechanical properties, formability, and anisotropy of dual phase $\mathrm{Mg}-7 \mathrm{Li}-1 \mathrm{Zn}$. Materials Research Express. Doi: 10.1088/2053-1591/ab2de6

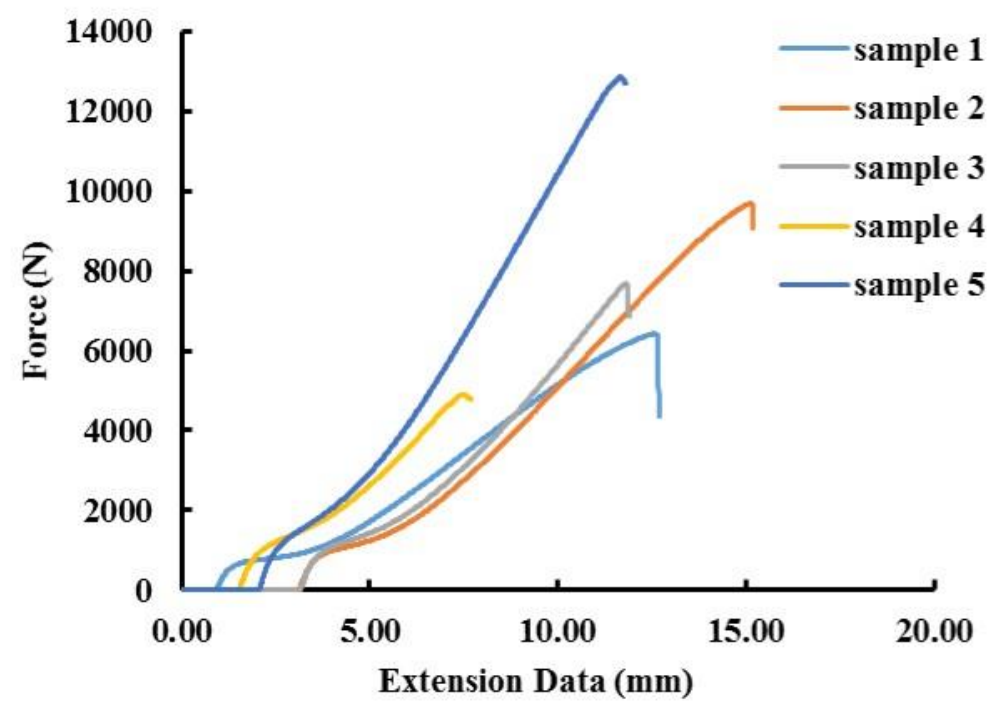

Fig.4 The force-displacement during the Nakazima test for different samples 
Preprint of: Davood Rahmatabadi, Ramin Hashemi, Moslem tayyebi and Abbas Bayati. (2019). Investigation of mechanical properties, formability, and anisotropy of dual phase $\mathrm{Mg}-7 \mathrm{Li}-1 \mathrm{Zn}$. Materials Research Express. Doi: 10.1088/2053-1591/ab2de6

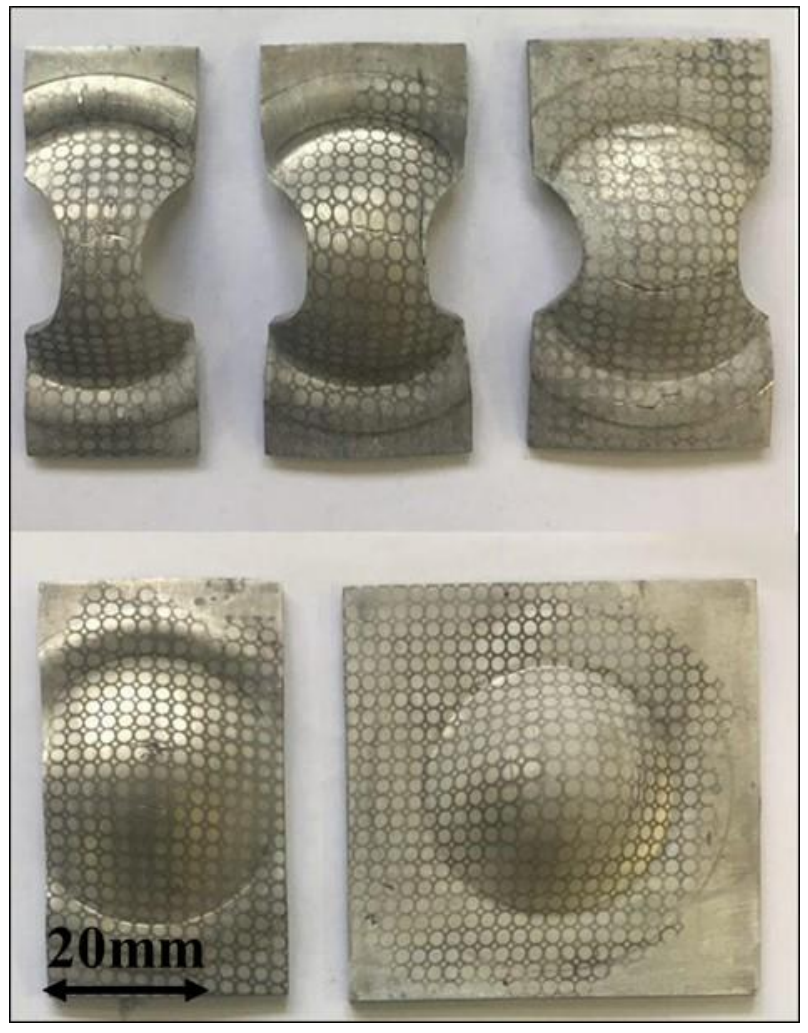

Fig.5 Typical processed specimens by the Nakazima test 
Preprint of: Davood Rahmatabadi, Ramin Hashemi, Moslem tayyebi and Abbas Bayati. (2019). Investigation of mechanical properties, formability, and anisotropy of dual phase $\mathrm{Mg}-7 \mathrm{Li}-1 \mathrm{Zn}$. Materials Research Express. Doi: $\underline{10.1088 / 2053-1591 / a b 2 d e 6}$

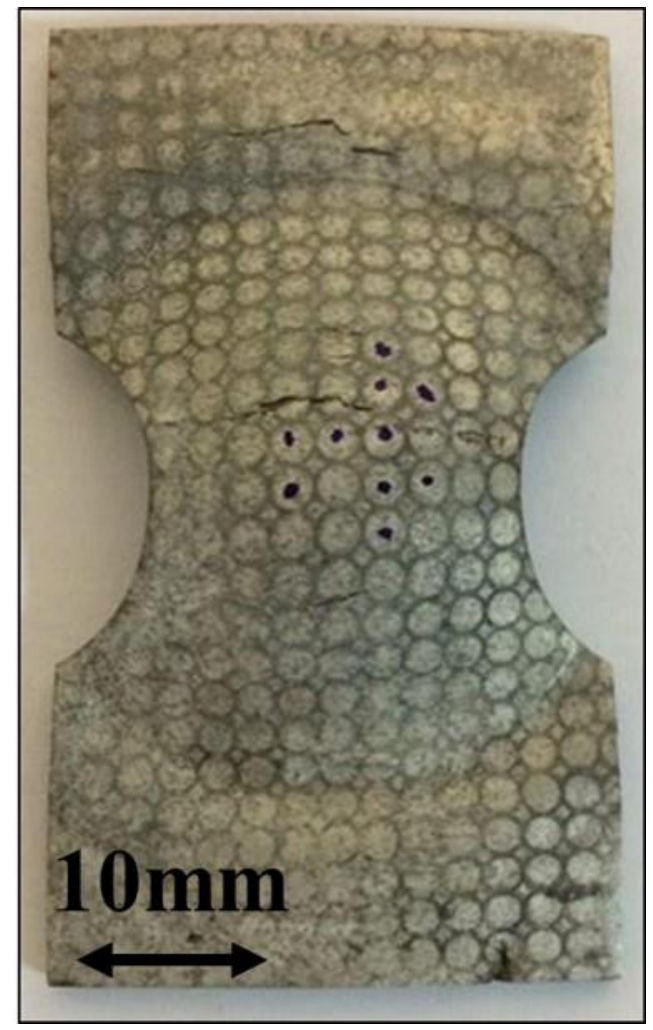

Fig.6 The necking and fracture points after the Nakazima test 
Preprint of: Davood Rahmatabadi, Ramin Hashemi, Moslem tayyebi and Abbas Bayati. (2019). Investigation of mechanical properties, formability, and anisotropy of dual phase $\mathrm{Mg}-7 \mathrm{Li}-1 \mathrm{Zn}$. Materials Research Express. Doi: 10.1088/2053-1591/ab2de6

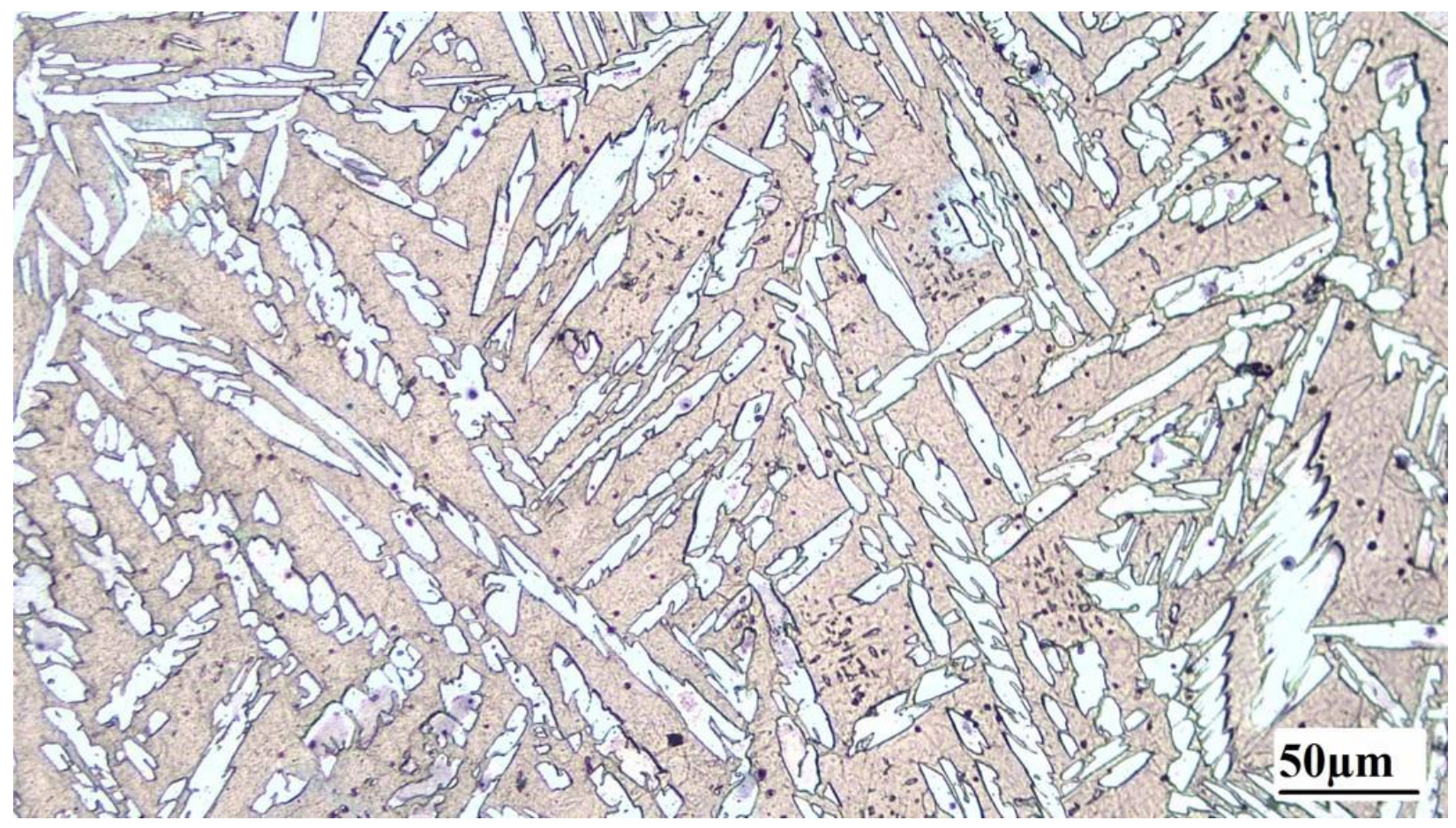

Fig.7 The microstructure of the as-cast $\mathrm{Mg}-7 \mathrm{Li}-1 \mathrm{Zn}$ 
Preprint of: Davood Rahmatabadi, Ramin Hashemi, Moslem tayyebi and Abbas Bayati. (2019). Investigation of mechanical properties, formability, and anisotropy of dual phase Mg-7Li-1Zn. Materials Research Express. Doi: 10.1088/2053-1591/ab2de6

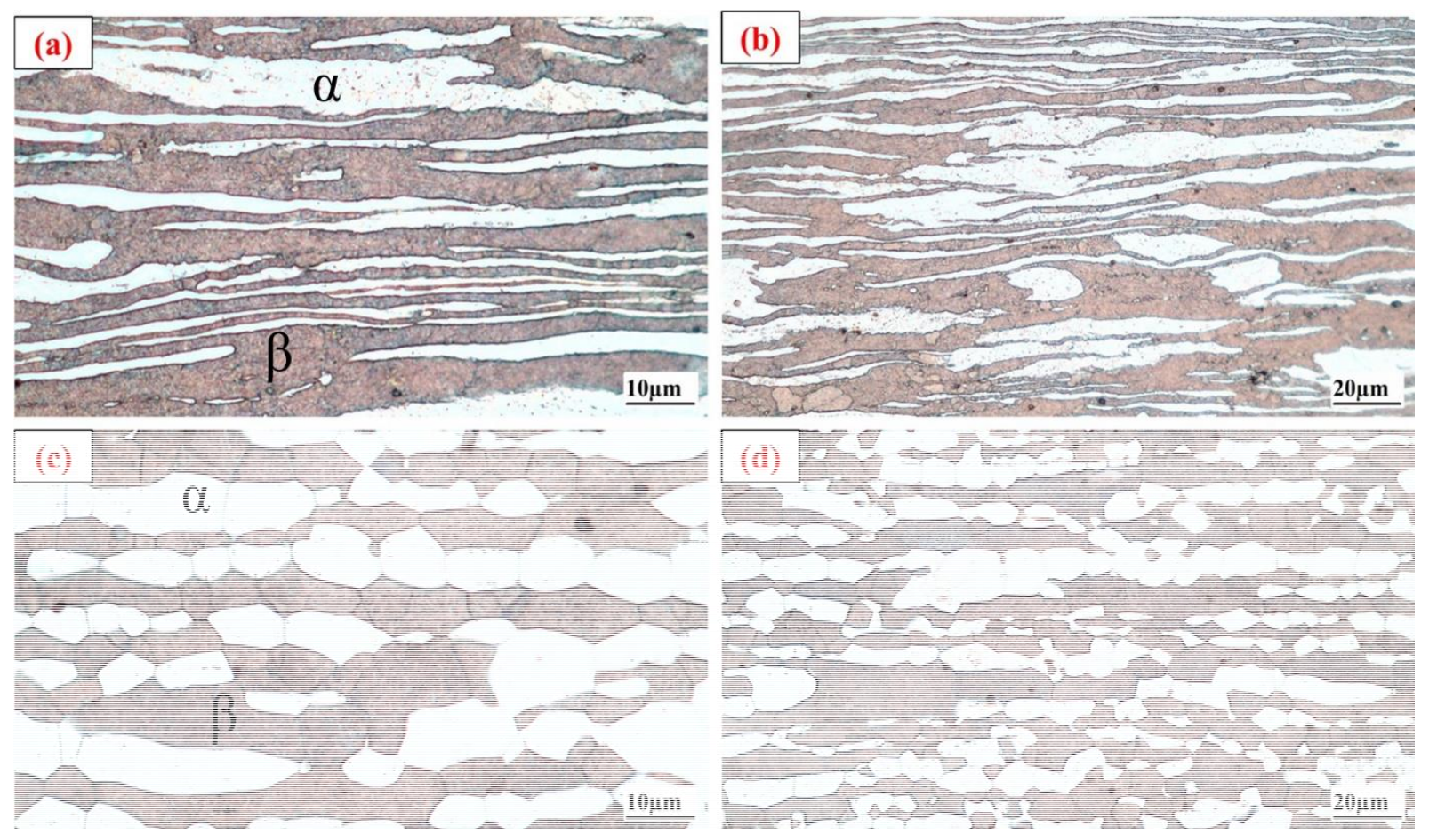

Fig.8 The microstructure of Mg-7Li-1Zn: (a) and (b) as rolled samples; (c) and (d) full annealed samples 
Preprint of: Davood Rahmatabadi, Ramin Hashemi, Moslem tayyebi and Abbas Bayati. (2019). Investigation of mechanical properties, formability, and anisotropy of dual phase $\mathrm{Mg}-7 \mathrm{Li}-1 \mathrm{Zn}$. Materials Research Express. Doi: 10.1088/2053-1591/ab2de6

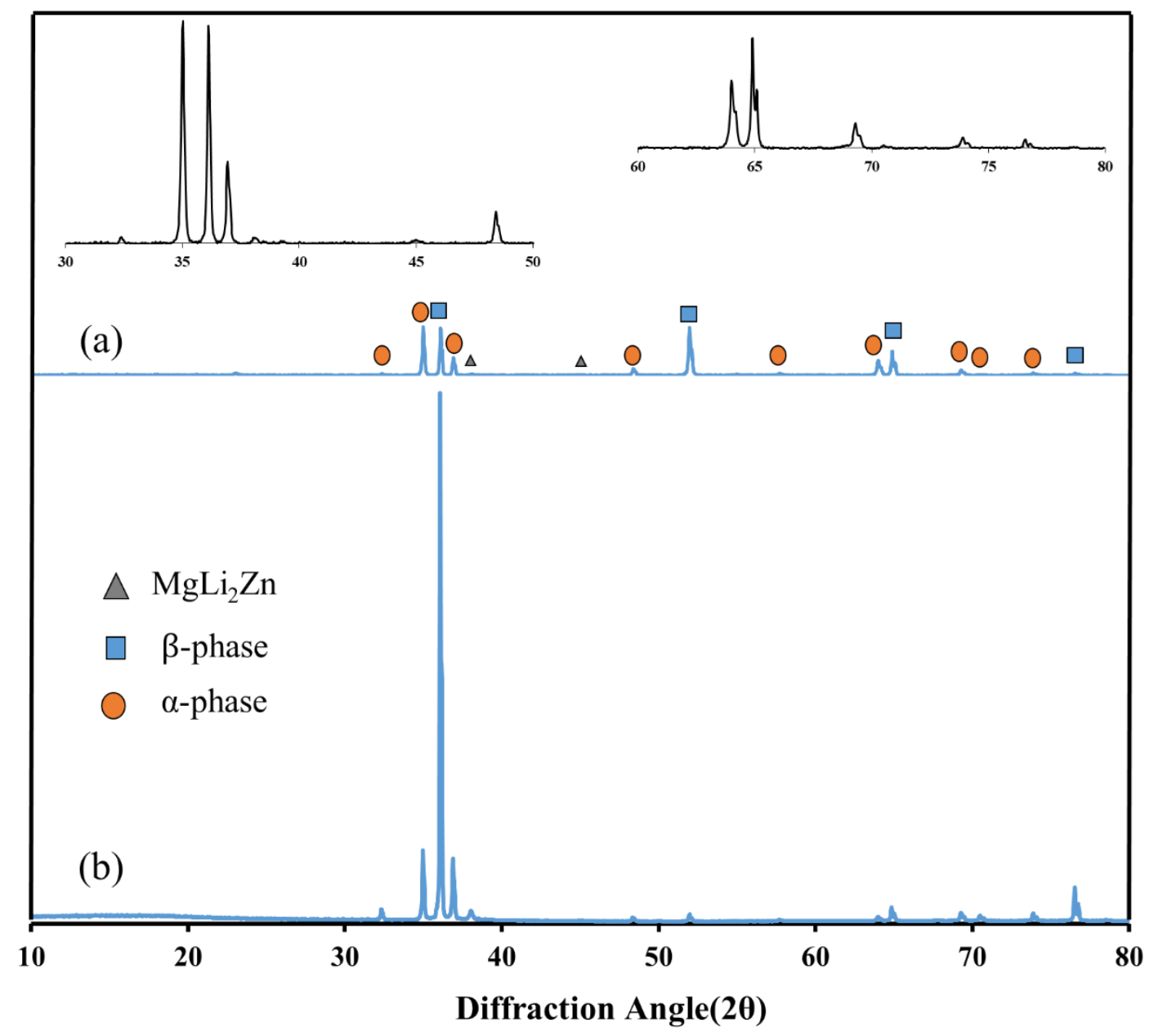

Fig.9 The X-ray-diffraction of the full annealed Mg-7Li-1Zn sample 
Preprint of: Davood Rahmatabadi, Ramin Hashemi, Moslem tayyebi and Abbas Bayati. (2019). Investigation of mechanical properties, formability, and anisotropy of dual phase $\mathrm{Mg}-7 \mathrm{Li}-1 \mathrm{Zn}$. Materials Research Express. Doi: 10.1088/2053-1591/ab2de6

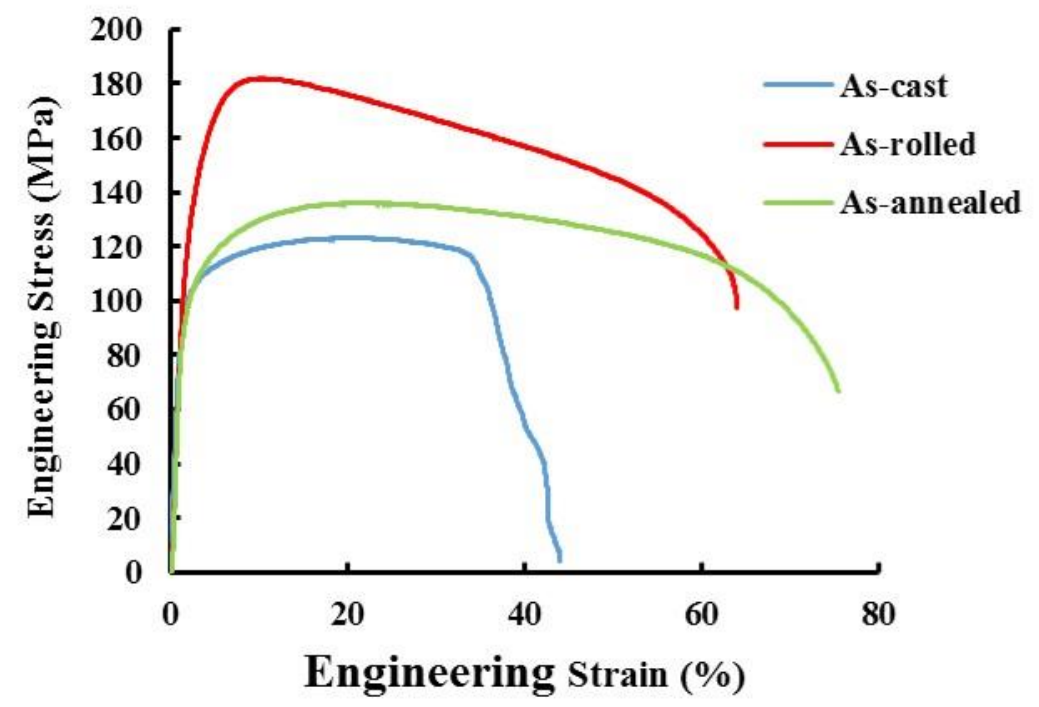

Fig.10 The engineering stress-strain curves of $\mathrm{Mg}-7 \mathrm{Li}-1 \mathrm{Zn}$ for three different situations (ascast, as-rolled and as-annealed samples) 
Preprint of: Davood Rahmatabadi, Ramin Hashemi, Moslem tayyebi and Abbas Bayati. (2019). Investigation of mechanical properties, formability, and anisotropy of dual phase $\mathrm{Mg}-7 \mathrm{Li}-1 \mathrm{Zn}$. Materials Research Express. Doi: 10.1088/2053-1591/ab2de6
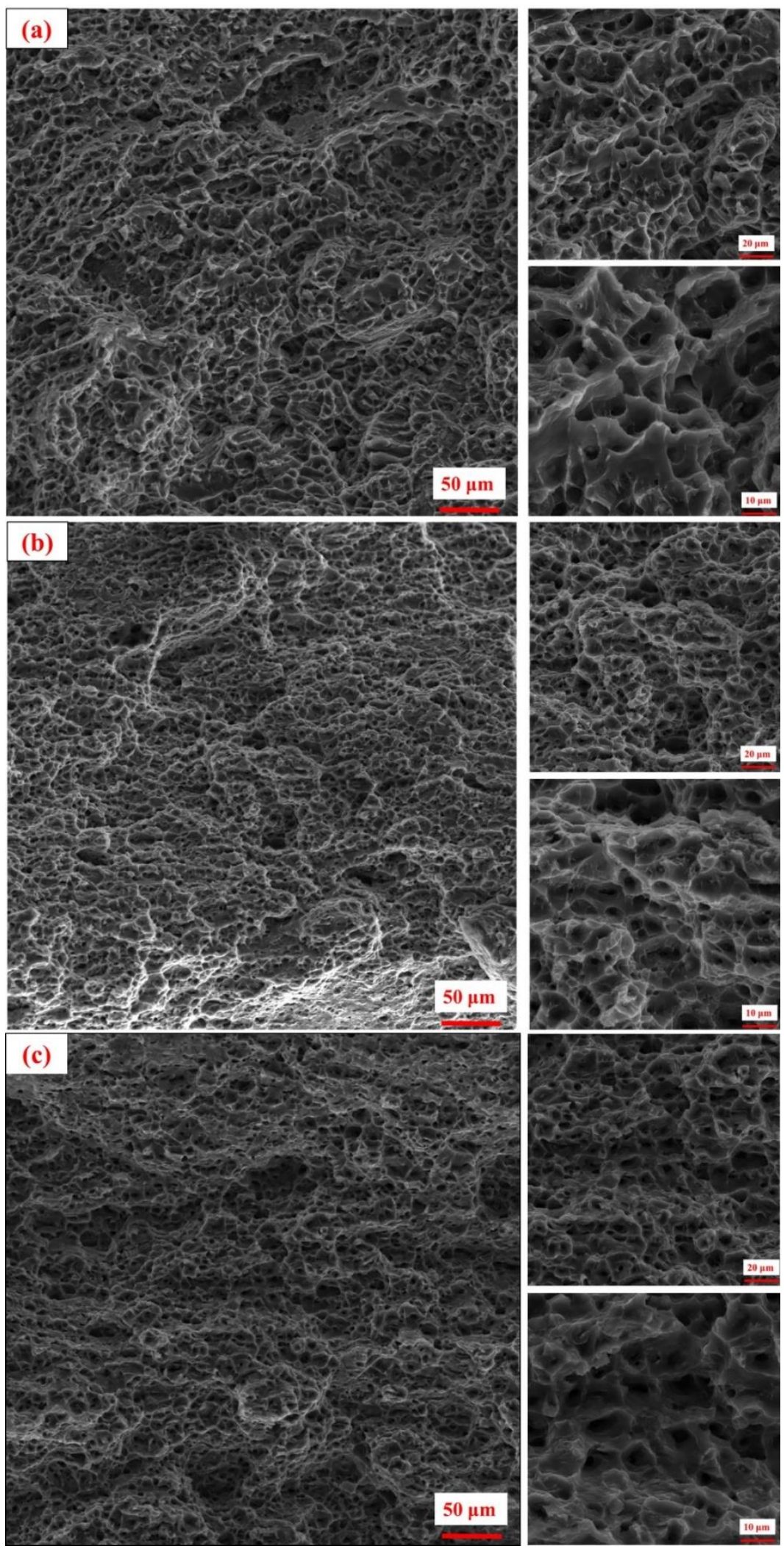
Preprint of: Davood Rahmatabadi, Ramin Hashemi, Moslem tayyebi and Abbas Bayati. (2019). Investigation of mechanical properties, formability, and anisotropy of dual phase $\mathrm{Mg}-7 \mathrm{Li}-1 \mathrm{Zn}$. Materials Research Express. Doi: 10.1088/2053-1591/ab2de6

Fig.11 The tensile fracture surfaces of $\mathrm{Mg}-7 \mathrm{Li}-1 \mathrm{Zn}$ for three different cases: (a) as-cast, (b) as-rolled, and (c) as-annealed samples

\section{Forming Limit Diagram (FLD)}

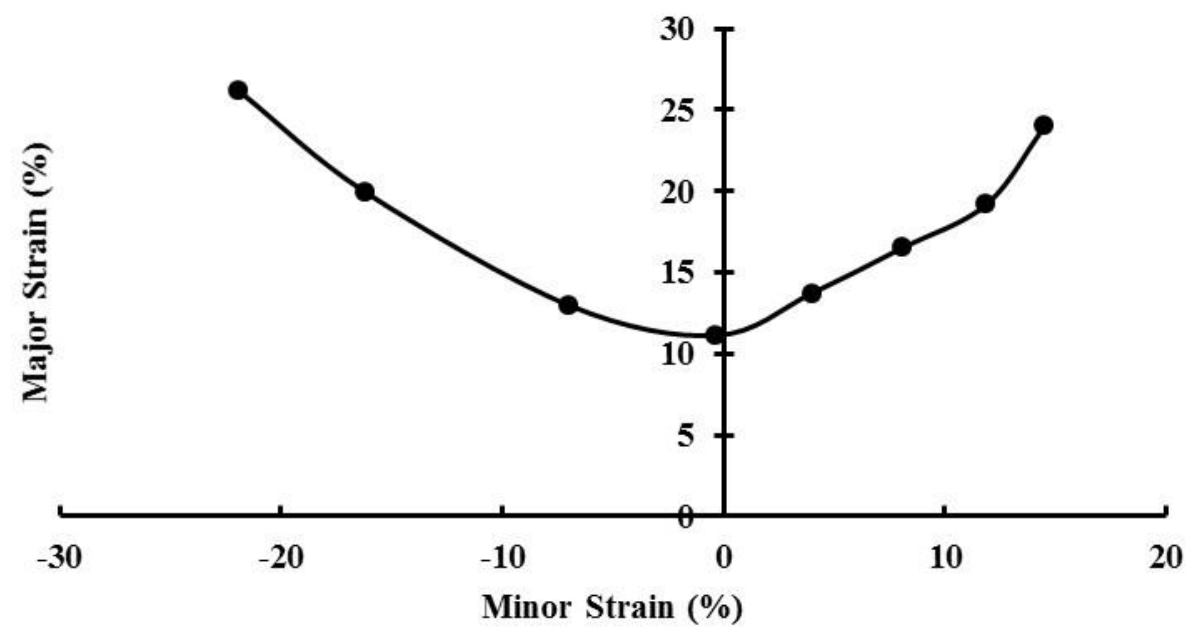

Fig.12 The forming limit diagram of as-annealed $\mathrm{Mg}-7 \mathrm{Li}-1 \mathrm{Zn}$ 
Preprint of: Davood Rahmatabadi, Ramin Hashemi, Moslem tayyebi and Abbas Bayati. (2019). Investigation of mechanical properties, formability, and anisotropy of dual phase $\mathrm{Mg}-7 \mathrm{Li}-1 \mathrm{Zn}$. Materials Research Express. Doi: 10.1088/2053-1591/ab2de6

Table 1: Summary of mechanical properties of previous researches for different dual phase Mg$\mathrm{Li}$ alloys processed by rolling and extrusion

\begin{tabular}{|c|c|c|c|c|}
\hline Materials & $\begin{array}{c}\text { The maximum value of ultimate } \\
\text { tensile strength (MPa) }\end{array}$ & $\begin{array}{c}\text { The maximum } \\
\text { value of } \\
\text { elongation }(\%)\end{array}$ & Processing method & Reference \\
\hline$\underset{n}{\operatorname{Mg6} 6 \operatorname{Li1} 1.1 Z}$ & 180 & 65 & Rolling & This study \\
\hline $\operatorname{Mg} 5 \mathrm{Li} 2 \mathrm{Zn}$ & 240 & 18 & Extrusion & [39] \\
\hline Mg8.5Li1Zn & 160 & 22 & Rolling & [40] \\
\hline Mg12Li1Zn & 125 & 56 & Rolling & [16] \\
\hline Mg6 Li1Zn & 155 & 32.2 & Rolling & {$[16]$} \\
\hline Mg9.5Li1Zn & 134 & 71.4 & Rolling & {$[40]$} \\
\hline$\underset{\mathrm{n}}{\mathrm{Mg} 3.5 \mathrm{Li} 0.5 \mathrm{Z}}$ & 205 & 22 & Extrusion & {$[41]$} \\
\hline Mg6.5Li2Zn & 185 & 38 & Extrusion & [41] \\
\hline$\underset{\mathrm{n}}{\operatorname{Mg} 6.5 \mathrm{Li} 0.5 \mathrm{Z}}$ & 150 & 24 & Extrusion & {$[41]$} \\
\hline $\mathrm{Mg} 3.5 \mathrm{Li} 2 \mathrm{Zn}$ & 165 & 22 & Extrusion & [41] \\
\hline Mg8.5Li1Zn & 130 & 63 & Rolling & [42] \\
\hline Mg8.5Li1Y & 120 & 64 & Extrusion & [43] \\
\hline $\mathrm{Mg} 8 \mathrm{Li} 3 \mathrm{Al}$ & 130 & 28 & Rolling & [44] \\
\hline $\mathrm{Mg} 8.5 \mathrm{Li} 2 \mathrm{Ce}$ & 160 & 20 & Extrusion & {$[45]$} \\
\hline
\end{tabular}


Preprint of: Davood Rahmatabadi, Ramin Hashemi, Moslem tayyebi and Abbas Bayati. (2019).

Investigation of mechanical properties, formability, and anisotropy of dual phase $\mathrm{Mg}-7 \mathrm{Li}-1 \mathrm{Zn}$.

Materials Research Express. Doi: 10.1088/2053-1591/ab2de6 
Preprint of: Davood Rahmatabadi, Ramin Hashemi, Moslem tayyebi and Abbas Bayati. (2019). Investigation of mechanical properties, formability, and anisotropy of dual phase $\mathrm{Mg}-7 \mathrm{Li}-1 \mathrm{Zn}$. Materials Research Express. Doi: 10.1088/2053-1591/ab2de6

Table 2: The anisotropy coefficients for as-cast, as-rolled and as-annealed $\mathrm{Mg}-7 \mathrm{Li}-1 \mathrm{Zn}$ samples

\begin{tabular}{|c|c|c|ccc|ccc|}
\hline \multirow{2}{*}{ Alloy } & Process & As-Cast & \multicolumn{3}{|c|}{ As-rolled } & \multicolumn{3}{|c|}{ As-annealed } \\
& Direction & NA & RD & $45^{\circ}$ & TD & RD & $45^{\circ}$ & TD \\
\hline \multirow{3}{*}{ LZ71 } & r-value & 1.018 & 3.494 & 4.103 & 1.931 & 1.052 & 1.061 & 1.055 \\
& $\mathbf{r}_{\mathbf{m}}$ & -- & & 3.408 & & & 1.057 \\
& $\mathbf{\Delta r}$ & -- & & 1.391 & & & 0.008 \\
& & & & & & & \\
\hline
\end{tabular}

